\title{
Quantitative analysis of phenolic compounds in Syrian olive mill wastewater by spectrophotometry and HPLC
}

\author{
Alaa Alfarawati ${ }^{*}$, Adnan A. Nizam and Nizar Issa
}

Department of Biology, Faculty of Science, University of Damascus, Syria

\section{A R T I C LE IN F O}

Article history:

Received 11 April 2013

Accepted 27 Augest 2013

Keywords:

Olive mill;

Wastewater;

Phenolic acids;

Ethylacetate.

\begin{abstract}
A B S T R A C T
Olive mill wastewater (OMW), generated by the oil extraction industry, represents a severe environmental problem due to its highly polluting organic load arising from phenols with low biodegradability. However, with its more than 30 phenols, OMW is regarded as a potential source of natural antioxidants.

This study aims to identify phenolic acids from Syrian OMW. The phenols were extracted using different solvents: methanol, chloroform and ethylacetate. High performance liquid chromatography (HPLC) and spectrophotometric approaches were used to determine the phenols of OMW samples. Ethylacetate is the best solvent with phenolic compounds $(493 \mathrm{mg} / 100 \mathrm{~g})$. The isolated phenolic acids were ellagic acid, chlorogenic acid, caffeic acid, p-coumaric acid, cinamic acid.
\end{abstract}

\section{Introduction}

The growing consumer demand for olive oil, as a consequence of its proved benefits for human health ${ }^{[1]}$, has become a positive factor for higher productions of this natural fat. Olive oil extraction industries are mainly located in Mediterranean countries: Spain, Italy, Greece, Portugal, Tunisia, Syria (4.8\%), Turkey, Morocco and Algeria ${ }^{[2]}$.

Olive oil production involves one of the following extraction processes: i) press olive oil extraction, ii) three-phase centrifugal olive oil extraction, and; iii) twophase centrifugal olive oil extraction. Each process generates waste products of different characteristics. Pressure and three-phase centrifugation systems produce considerably more liquid effluent which is so-called olive mill wastewater (OMW), vegetation water, or alpechin than the two-phase centrifugation process ${ }^{[3,4]}$. The properties of OMW vary enormously with type of the process, climatic conditions and region.

The production process of olive oil usually yields next to $20 \%$ olive oil, a $30 \%$ semi-solid waste and $50 \%$ aqueous liquor ${ }^{[3]}$. Three-phase extraction systems involve the addition of large amounts of water (up to 50 $\mathrm{L} / 100 \mathrm{~kg}$ olive paste), resulting in the worldwide production of more than 30 million $\mathrm{m}^{3}$ per year of OMW ${ }^{[5]}$.

OMW is a dark red- to black- colored, acidic ( $\mathrm{pH} 3$ - 6) liquid of high conductivity. This black wastewater liquid

* Corresponding author.

E-mail address: Alaa.alfarawati@yahoo.com is highly pollutant, since it presents high Biological oxygen demand (BOD) values $\left(50-100 \mathrm{~g} \mathrm{O}_{2} / \mathrm{L}\right)$ as well as chemical oxygen demand (COD) values $(80-200 \mathrm{~g}$ $\left.\mathrm{O}_{2} / \mathrm{L}\right)^{[6]}$. These are $200-400$ times higher than those of a typical municipal sewage ${ }^{[7]}$.

The low $\mathrm{pH}$ and the high amounts of organic matter include sugars, tannins, phenols, polyalcohols, pectins, and lipids ${ }^{[8]}$ make it very difficult to be purified. Deterioration of natural water bodies due to olive mill wastes is a serious problem as indicated by coloring, appearance of an oily shine, and increased oxygen demand.

The powerful pollutants prohibit OMW to be directly discharged into water or onto land. Several treatment procedures including physical, chemical, biological or combined technologies have been tested to reduce undesirable properties of OMW prior to disposal.

The major factor of the environmental problem is because of the high phenols of OMW streams, that is to say it may contain up to $10 \mathrm{~g} / \mathrm{L}$ of phenols ${ }^{[9]}$. These compounds are difficult to decompose ${ }^{[10]}$ and present phytotoxicity ${ }^{[11,12]}$, toxicity against aquatic organisms ${ }^{13]}$, or suppression of soil microorganisms ${ }^{[14]}$. The olive fruit is very rich in phenols, but only $2 \%$ of the total phenols of the olive fruit pass in the oil phase, while the remaining amount is lost in the OMW (approx. 53\%) and in the pomace (approx. 45\%) ${ }^{[15]}$.

In general, phenols are thought to deliver health benefits by several mechanisms, including: (1) direct free radical quenching, (2) protection and regeneration of other 
dietary antioxidants, (3) chelation of metal ions. So they act as antibiotic/antiviral, anti-inflammatory, and protective agents from diseases ${ }^{[16,17]}$. Notably, OMW can provide a cheap source of phenols with strong antioxidant properties.

Olive phenols are biologically active compounds and contain numerous simple and complex substances that are characterized by multifunctional moieties. The simple phenols such as vanillic acid, gallic acid, cumaric acid, caffeic acid, tyrosol and hydroxytyrosol possess alkene, alcoholic, and carboxylic groups whereas more complex phenols such as secoiridoids (oleuropein and ligstroside) possess glycosidic and monoterpenoid units ${ }^{[18]}$.

Recovery of phenols from OMW by means of appropriate technologies will not only avoid waste disposal problem, but also will allow obtaining addedvalue phenols as by-products. These phenols may be used as natural ingredients in variety of food products to enhance their quality.

The present study deals with the identification of phenolic acids by spectrophotometry and HPLC from OMW.

\section{Materials and Methods}

Chemicals and reagents: All chemicals and reagents used were either analytical or HPLC grade. The Folin Ciocalteu phenol reagent, gallic acid and phosphoric acid were purchased from Sigma-Aldrich (St. Louis, USA). Analytical grade of hydrochloric acid, sodium hydroxide, sodium carbonate, methanol, chloroform and ethylacetate were purchased from Merck (Merck, Darmstadt, Germany).

OMW samples preparation: OMW was collected from olive mill press located in Sweida - Syria. The OMW was stored in closed plastic containers in the dark at $4^{\circ} \mathrm{C}$.

Extraction of phenolic compounds: A modification of procedure for extraction of phenols published by Winkelhausen et al., ${ }^{[19]}$ was employed. In the first step, the samples were extracted, three times successively, with hexane in the ratio $1: 4(\mathrm{v} / \mathrm{v})$ for OMW to remove the residual oil and pigments. In the second step, the phenols were extracted from the samples using methanol adjusted to $\mathrm{pH} 9$ with $\mathrm{NaOH}$. The ratio of OMW and methanol was 1:6 (v/v). After two successive extractions, the total methanol extract was filtered $(0.45 \mu \mathrm{m})$ and then concentrated by a rotary-evaporator model IKA RV 10 digital with oil free air compressor model SL400G $220 \mathrm{v} 50 \mathrm{~Hz}$ with integrated heating bath $\mathrm{HB} 10$ digital (3 liters) at $30^{\circ} \mathrm{C}$ and $45 \mathrm{rpm}$ until we get the dry residue and then dissolved in $25 \mathrm{ml}$ methanol. Also, phenols were extracted in OMW according to Winkelhausen et al., [19]. The samples were extracted, three times successively, with hexane in the ratio $1: 4(\mathrm{v} / \mathrm{v})$ for OMW to remove the residual oil and pigments. In the next step, phenols were extracted from the samples using chloroform. The ratio of OMW and chloroform was 1:6 (v/v). After two successive extractions, the total chloroform extract was filtered $(0.45 \mu \mathrm{m})$ and then concentrated by a rotary-evaporator model IKA RV 10 digital with oil free air compressor model SL400G 220v $50 \mathrm{~Hz}$ with integrated heating bath HB 10 digital (3 liters) at $30^{\circ} \mathrm{C}$ and $45 \mathrm{rpm}$ until we get the dry residue and then dissolved in $25 \mathrm{ml}$ methanol. Finally, phenols were extracted in OMW using ethylacetate according to the method of Elena De Marco et al., ${ }^{[20]}$. Ten ml of OMW were mixed with $15 \mathrm{ml}$ of hexane; the mixture was vigorously shaken and centrifuged for $5 \mathrm{~min}$ at $3000 \mathrm{rpm}$. The phases were separated and washing was repeated two times successively. Extraction of phenols was then carried out with $10 \mathrm{ml}$ of ethylacetate after acidification by $\mathrm{HCl}$ to $\mathrm{pH} 2$. The phases were separated and the extraction was repeated four times successively. The ethylacetate was evaporated under vacuum and the dry residue was dissolved in $3 \mathrm{ml}$ of methanol and this solution was used for determination of phenols.

Determination of total phenols in olive extracts: Phenol concentrations were determinated using the FolinCiocalteu assay ${ }^{[21]}$. The Folin-Ciocalteu method (FCM), based on the reduction of a phosphowolframatephosphomolybdate complex by phenols to blue reaction products, was used to determine phenols. Briefly, $3 \mathrm{ml}$ of Nanopure water, $2 \mathrm{ml}$ of sample, and $0.2 \mathrm{ml}$ of FolinCiocalteu reagent were added to a $10 \mathrm{ml}$ volumetric flask. The contents were mixed and allowed to stand for 5-8 min at room temperature. Next, $4 \mathrm{ml}$ of a 7\% sodium carbonate solution was added, followed by the addition of Nanopure water filled to volume. Solutions were mixed and allowed to stand at room temperature for $2 \mathrm{~h}$. Sample aliquots were filtered through a Whatman 0.45 $\mu \mathrm{m}$ (polytetrafluoroethylene) filter prior to the determination of phenols' concentration using a Beckman DU 7400 spectrophotometer monitoring at 750 $\mathrm{nm}$ against blank (100 $\mu \mathrm{l}$ water). The absorbance was measured twice for each sample. The absorbance of the samples was compared with calibration curve to obtain the phenols' content. The calibration curve was prepared using gallic acid as the standard phenol at concentrations of $0.2,0.4,0.6,0.8$ and $1 \mathrm{mM}$. The absorbance was determined at $306 \mathrm{~nm}$. The linearity range for this assay is shown in Fig.1 with $\left(\mathrm{R}^{2}=0.9990\right)$.

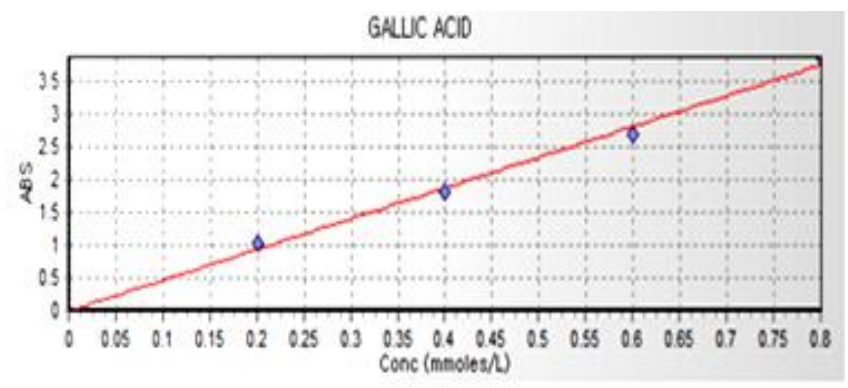

Fig. 1: The calibration curve using gallic acid. 
HPLC analysis: The OMW phenols' analysis was performed in liquid chromatography equipped with Varian Pump model 9010, Rheodyne injector, DyodeArray detector Varian ProStar model 330, column Heater Jones Chromatography model 7981 and using LC WorkStation Software. The analyses were carried out with the internal standard calibration method. The sample was injected in the HPLC system with a C18 column (Merck LichroCart 125-3), thermostated at $35.2^{\circ} \mathrm{C}$. The mobile phase consisted of phosphoric acid at $\mathrm{pH} 2.5$ (eluent A) and methanol (eluent B). The injection volume for all samples was $10 \mu \mathrm{l}$. The elution was done with flow rate $0.5 \mathrm{ml} / \mathrm{min}$ and the gradient program was as follows: $95-83 \%$ A (10 $\mathrm{min}), 83-74 \%$ A (10 min), 74-42\% A (20 min), 42-5\% A (10 min) and 5-95\% A (10 min). The phenols' analyses were done at $280 \mathrm{~nm}$ and identification was carried out using the peek retention time and spectrum compared with those from commercial standards ${ }^{[22]}$.

\section{Results and discussion}

Using the system setup and methods described, it was possible to extract phenols in the samples. The dry weight and the percentage are shown in Table 1.

According to the dry weight for the extracts, chloroform extract had the highest phenols $(8 \% \mathrm{w} / \mathrm{v})$ while the other extracts presents in lesser amount.

Total phenol contents of OMW

Comparing with the results in dry weight, the larger amount of phenols must be in chloroform, but chloroform can extract other components in OMW, so we cannot take the dry weight as a standard to determine the amount of phenols. The total phenol contents must be determined in the samples by Folin method. The calibration curve using gallic acid (Fig.1) gives the formula $(\mathrm{AbS}=4.699 * \mathrm{C})$. The total phenols of different extracts are shown in Table 2.

Ethylacetate extract had the highest Phenols (493 $\mathrm{mg} / 100 \mathrm{~g})$. On the other hand, methanol and chloroform were present in lesser extent than ethylacetate (Table 2).

Solvents with relatively lower polarity like ethylacetate were more efficient in general for extracting phenols [23,24] in OMW. On the other hand, pure solvents with higher polarity extracted significantly higher amounts of phenols than non-polar solvent. Chloroform is considered as a non-polar solvent while ethylacetate is considered as an aprotic solvent and methanol is considered as a protic solvent. The solvent most suitable for the extraction of phenols appeared to be ethylacetate in OMW ${ }^{[24]}$, and that what can explain the ability of chloroform to extract larger amount of phenol than methanol in this study.

The presented results conform to those of another study, that ethylacetate exhibits a higher extraction power compared to other solvents such as methyl isobutyl ketone, methyl ethyl ketone, and diethyl ether, which was shown by Allouche ${ }^{[25]}$.

Based on the abovementioned results, HPLC analysis was employed to define the qualitative content of phenolic acids in the ethylacetate extract in OMW.

Table 1: Percentage and dry weight for phenols extracts using ethylacetate, chloroform and methanol.

\begin{tabular}{clccc}
\hline Sample & Solvent & Volume $(\mathbf{m l})$ & Dry weight $(\mathbf{g} / \mathbf{m l})$ & \% extract $(\mathbf{w} / \mathbf{v})$ \\
\hline \multirow{2}{*}{ OMW } & Ethylacetate & 50 & 1.3 & 2.6 \\
& Chloroform & 50 & 4 & 8 \\
& Methanol & 50 & 2.8 & 5.6 \\
\hline
\end{tabular}

Table 2: Total phenol contents $(\mathrm{C})$ in $\mathrm{mg} / 100 \mathrm{~g}$ of dry weight at absorbent on $750 \mathrm{~nm}$ at concentration $10 \mathrm{mM}$ for each solvent.

\begin{tabular}{lccc}
\hline Solvent & Concentration mM & AbS (750 nm) & $\begin{array}{c}\text { C Total phenol content (mg/100g } \\
\text { dry weight) }\end{array}$ \\
\hline Ethylacetate & 10 & 1.395 & 493 \\
Chloroform & 10 & 0.950 & 340 \\
Methanol & 10 & 0.919 & 333 \\
\hline
\end{tabular}




\section{HPLC analysis for OMW extract}

HPLC chromatogram are presented in Fig. 2, ellagic acid, chlorogenic, caffeic, p-coumaric, and cinnamic acids were identified in the investigated extracts by comparing their retention times (RT) and on-line ultraviolet (UV) spectra with those of standards Fig. 3 .

The benzoic group appeared before the cinnamic acid group because the first has low molecular weight and higher polarity coming from large number of $\mathrm{OH}$ radical in the benzoic group.

These identified phenols were already reported in OMW except for ellagic and chlorogenic acid. (Table 3). Ellagic and chlorogenic acid were first reported in this study. Retention times for the identified phenolic acids are shown in Table 4.

\section{Conclusions}

Extraction for phenols and determination for phenolic acids from Syrian OMW was achieved using three solvents. Ethylacetate was the solvent in extracting phenols with concentration of $(493 \mathrm{mg} / 100 \mathrm{~g})$. HPLC has appeared to be a simple and sensitive tool for the determination of phenolic acids since it showed unreported phenoic acids (ellagic and chlorogenic acids) in Syrian OMW.

We recommend studying the following parameters and their effect on the constituents obtained and their respective concentrations: (a) effect of method of olive oil pressing, (b) type of olive trees, (c) age of olive trees, (d) area where olive trees are grown, and (e) storage of wastewater.

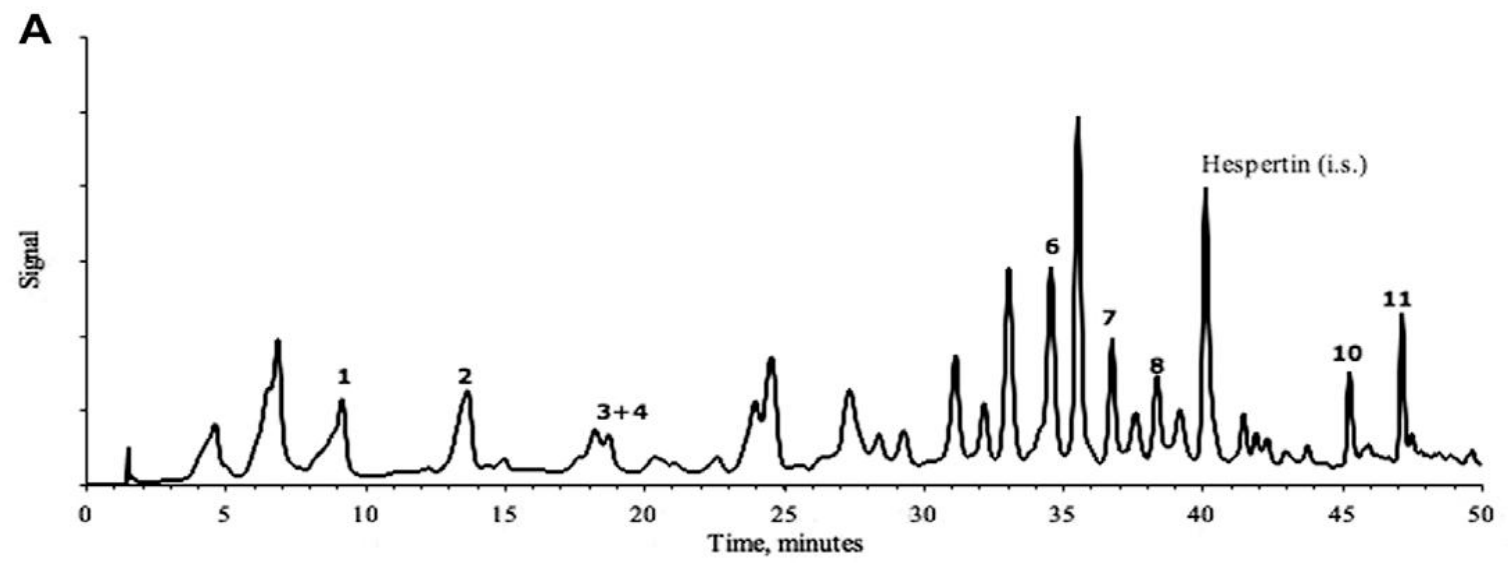

Fig.2: Typical HPLC chromatogram of phenols from Montesinho Natural Park. Phenolic acids are: (1) protocatequic acid, (2) phydroxibenzoic acid, (3) caffeic acid, (4) chlorogenic acid, (5) p-coumaric acid, (6) ellagic acid and (7) cinnamic acid. Flavonoids are: (8) naringenin, (9) kaempferol, (10) pinocembrin and (11) chrysin. ${ }^{[22]}$.

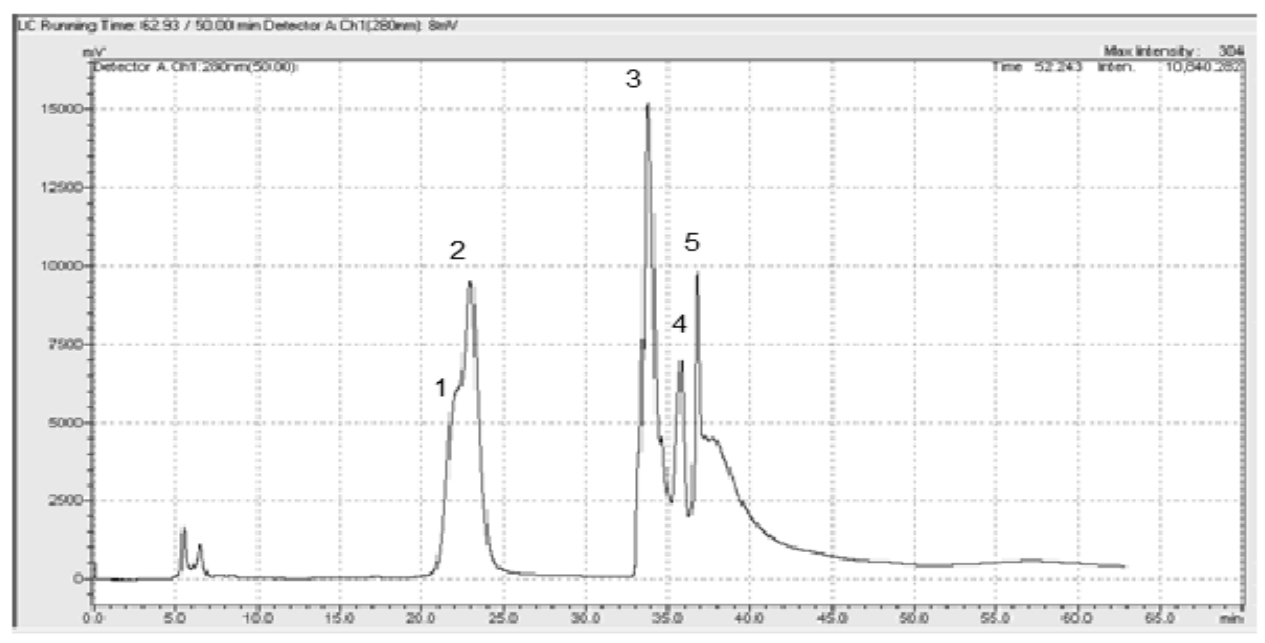

Fig.3: (1) Caffeic acid, (2) Chlorogenic acid, (3) p-coumaric acid, (4) Ellagic acid, (5) Cinnamic acid.

Table 3: References of phenolic acids.

\begin{tabular}{|l|c|}
\hline Phenolic acid compounds & References \\
\hline Caffeic acid & {$[26-32]$} \\
\hline p-Coumaric acid & {$[27,29-32]$} \\
\hline (Cinnamic acid) ferulic and sinapic acid & {$[29,31-34]$} \\
\hline
\end{tabular}


Table 4: RT for the identified phenolic acids.

\begin{tabular}{|l|c|}
\hline Phenolic acid & Retention time, RT \\
\hline Caffeic acid & 18 \\
\hline Chlorogenic acid & 19 \\
\hline p-Coumaric acid & 34 \\
\hline Ellagic acid & 35 \\
\hline Cinnamic acid & 36 \\
\hline
\end{tabular}

\section{References}

1) Tuck, L. and Hayball, J. (2002). Major phenolic compounds in olive oil: metabolism and health effects. The Journal of Naturitional Biochemistry, 13: 636-644.

2) http://www.internationaloliveoil.org/estaticos/view/ 130-survey-and-assessment-division.

3) Niaounakis, M. and Halvadakis, C.P. (2006). Olive processing waste management literature review and patent survey. 2nd ed, Elsevier: Waste Management

4) McNamara, J., Anastasiou, C., O'Flaherty, V. and Mitchell, R. (2008). Bioremediation of olive mill wastewater. Int. Biodet. Biodeg., 61: 127-134.

5) Borja, R., Alba, J. and Banks, J. (1997). Impact of the main phenolic compounds of olive mill wastewater (OMW) on the kinetics of acetoclastic methanogenesis. Process Biochemistry, 32: 121133.

6) Khoufi, S., Aloui, F. and Sayadi, S. (2006). Treatment of olive oil mill wastewater by combined process electro-Fenton reaction and anaerobic digestion. Water Research, 40: 2007-2016.

7) Cossu, R., Blakey, N. and Cannas, P. (1993). Influence of co-disposal of municipal solid waste and olive vegetation water on the anaerobic digestion of a sanitary landfill. Water Sci. Technol., 27: 261-271.

8) D’Annibale, A., Crestini, C., Vinciguerra, V., Giovannozzi and Sermanni, G. (1998). The biodegradation of recalcitrant effluents from an olive mill by a white-rot fungus. Journal of Biotechnology, 61: 209-218.

9) Roig, A., Cayuela, L. and Sanchez-Monedero, A. (2006). An overview on olive mill wastes and their valorisation methods. Waste Management, 26: 960969.

10) Obied, K., Allen, S., Bedgood, R., Prenzler, D., Robards, K. and Stockmann, R. (2005). Bioactivity and analysis of biophenols recovered from olive mill waste. Journal of Agricultural and Food Chemistr, 53: 823-837, 2005.

11) Capasso, R., Cristinzio, G., Evidente, A. and Scognamiglio, F. (1992). Isolation, spectroscopy and selective phytotoxic effects of polyphenols from vegetable waste waters. Phytochemistry, 31: 41254128.
12) Aliotta, G., Fiorentino, A., Oliva, A. and Temussi, F. (2002). Olive oil mill wastewater: isolation of polyphenols and their phytotoxicity in vitro. Allelopathy Journal, 9: 9-17.

13) Fiorentino, A., Gentili, A. and Isidori, M. (2003). Environmental effects caused by olive mill wastewaters: toxicity comparison of low-molecularweight phenol components. Journal of Agricultural and Food Chemistry, 51: 1005-1009.

14) Kotsou, M., Mari, I., Lasaridi, K., Chatzipavlidis, I., Balis, C. and Kyriacou A. (2004). The effect of olive oil mill wastewater (OMW) on soil microbial communities and suppressiveness against Rhizoctonia solani. Applied Soil Ecology, 26: 113121.

15) Rodis, S., Karathanos, T. and Mantzavinou, A. (2002). Partitioning of olive oil antioxidants between oil and water phases. Journal of Agricultural and Food Chemistry, 50: 596-601.

16) Bravo, L. (1998). Polyphenols: chemistry, dietary sources, metabolism, and nutritional significance. Nutrition Reviews, 56: 317-333.

17) Scalbert, A., Manach, C., Morand, C., R'em esy, C. and Jim'enez L. (2005). Dietary polyphenols and the prevention of diseases.Critical Reviews in Food Science and Nutrition, 45: 287-306.

18) Bianco, A. and Uccella, N. (2000). Biophenolic components of olives. Food Res Int., 33: 475485.

19) Winkelhausen, E., Pospiech, R. and Laufenberg G. (2005). Antifungal activity of phenolic compounds extracted from dried olive pomace. Bulletin of the Chemist and Technologist of Macedonia, 24: 41-46.

20) Elena De Marco, Savarese, M., Paduano, A. and Sacchi, R. (2007). Characterization and fractionation of phenolic compounds extracted from olive oil mill wastewaters. Food Chemistry, 104: 858-867.

21) Singleton, L. and Rossi, A. (1965). Colorimetry of total phenolics with phosphomolybdic phosphotungstic acid reagents. American Journal of Enology and Viticulture, 16: 144-158.

22) Yao, L., Datta, N., Toms-Barbern, A., Ferreres, F., Martos, I. and Singanusong, R. (2003). Flavonoids, phenolic acids and abscisic acid in Australian and New Zealand Leptospermum honeys. Food Chemistry, 81; 159-168. 
23) Afify, S., Mahmoud, A., Emara, A. and Abdelkreem, I. (2009). Phenolic Compounds and COD Removal from Olive Mill Wastewater by Chemical and Biological Procedures, Australian Journal of Basic and Applied Sciences, 3: 10871095.

24) Sahin, S., Isik, E. and Demir, C. (2012). Prediction of total phenolic content in extracts of Prunella species from HPLC profiles by multivariate calibration. ISRN Chromatography.

25) Allouche, N., Fki, I. and Sayadi, S. (2004). Toward a high yield recovery of antioxidants and purified hydroxytyrosol from olive mill wastewaters. Journal of Agricultural and Food Chemistry, 52: 267-273.

26) Visioli, F., Vincieri, F. and Galli, C. (1995). "Wastewaters", from olive oil production are rich in natural antioxidants. Experientia, 51: 32-34.

27) Aramendia, A., Bora'u, V., Garcı'a, I., Jiménez, C., Lafont, F., Marinas, M. and Urbano, J. (1996). Qualitative and quantitative analysis of phenolic compounds by high performance liquid chromatography and detection with atmospheric pressure chemical ionization mass spectrometry. Rapid Commun. Mass Spectrom., 10: 1585-1590.

28) Servili, M., Baldioli, M., Selvaggini, R., Miniati, E., Macchioni, A. and Montedoro, F. (1999). High performance liquid chromatography evaluation of phenols in olive fruit, virgin oil, vegetation waters and pomace in 1D- and 2D Nuclear Magnetic Resonance characterization. Journal of agricultural and food chemistry, 47: 12-18.

29) Sayadi, S., Allouche, N. and Jaoua, M. (2000). Detrimental effects of high molecular-mass polyphenols on olive mill wastewater biotreatment. Process Biochem., 35: 725-735.

30) Lesage-Meessen, L., Navarro, D., Maunier, S., Sigoillot, C., Lorquin, J., Delattre, M., Simon, L., Asther, M. and Labat, M. (2001). Simple phenolic content in olive oil residues as a function of extraction systems. Food Chem., 75: 501-507.

31) Della Greca, M., Monaco, P., Pinto, G., Pollio, A., Previtera, L. and Temussi, F. (2001). Phytotoxicity of low-molecular-weight phenols from olive mill waste waters. Bull. Environ. Toxicol., 67: 352-359.

32) Della Greca, M., Previtera, L., Temussi, F. and Zarrelli, A. (2004). Low-molecular-weight components of olive oil mill waste-waters. Phytochemical analysis, 15: 184-188.

33) Martı́nez-Nieto, L., Garrido-Hoyos, E., Camacho Rubio, F., Garcı'a-Pareja, P. and RamosCormenzana, A. (1993). Biological purification of waste products from olive extraction. Bioresourc. Technol., 43: 215-219.

34) Pe'rez, J., Rubia, T. de la., Moreno, J. and Martínez, J. (1992). Phenolic content and antibacterial activity of olive oil waste waters. Environmental Toxicology and Chemistry, 11: 489495. 